\title{
ESTUDOS
}

\section{Processos de formação de professoras iniciantes}

Maévi Anabel Nono

Maria da Graça Nicoletti Mizukami

\section{Resumo}

Estudos têm evidenciado a importância dos primeiros anos de profissão nos processos de formação docente. Neste artigo, são analisados processos formativos de professoras iniciantes que atuam na educação infantil e nos anos iniciais do ensino fundamental, a partir de dados obtidos em pesquisa realizada no período 2001-2005. Casos de ensino foram utilizados como instrumentos de pesquisa e permitiram que as iniciantes realizassem descrições e análises de suas trajetórias profissionais. As professoras explicitaram dúvidas, certezas, equívocos e contradições que orientam e caracterizam suas práticas docentes nos primeiros anos de docência. Explicitaram, ainda, conhecimentos referentes ao modo como ensinam conteúdos matemáticos e de linguagem escrita.

Palavras-chave: formação de professores; professoras iniciantes.

\section{Abstract \\ Profissional knowledge of beginning teachers}

Studies have evidenced the importance the first years of the teaching career in the formative processes. This article discusses the professional knowledge of beginning teachers of the Elementary and Primary School. It is based on research developed during 2001-2005. One can said that the teaching cases used in the research allowed the beginning teachers to describe and analyze their own professional trajectories. The teachers exposed doubts, certainties, mistakes and contradictions that guided and characterized their professional practice. Teachers pointed out the knowledge regarding the way they teach mathematical and Portuguese written language contents.

Keywords: teacher education; beginning teachers.

\section{Considerações iniciais}

Diversos estudos têm apontado a importância da investigação de aspectos relativos à etapa de iniciação na carreira docente (Huberman, 1993; Imbernón, 2001; Marcelo Garcia, 1999). Neste artigo, são analisados processos formativos de professoras iniciantes que atuam na educação infantil e nos anos iniciais do ensino fundamental, a partir de dados obtidos em pesquisa realizada, no período 2001-2005, com a utilização de casos de ensino como instrumentos de pesquisa (Nono, 2005). 


\section{Estudos sobre formação de professores e início na carreira docente}

Conforme assinala Marcelo Garcia (1999, p. 112),

[...] falar da carreira docente não é mais do que reconhecer que os professores, do ponto de vista do "aprender a ensinar", passam por diferentes etapas, as quais representam exigências pessoais, profissionais, organizacionais, contextuais, psicológicas, etc., específicas e diferenciadas.

Nesse sentido, as preocupações norteadoras das pesquisas sobre formação de professores têm se ampliado cada vez mais, girando, atualmente, não apenas em torno dos cursos de formação inicial e de questões relativas aos futuros professores, mas englobando, também, temáticas relacionadas com os professores principiantes e os professores em exercício.

Nos diferentes momentos de sua carreira profissional - formação inicial, início na carreira, etapa em que já possui certa estabilidade profissional, período em que questiona sua opção profissional, período em que se aproxima de sua aposentadoria -, o professor enfrenta diferentes necessidades, problemas, expectativas, desafios, dilemas, e vai construindo seu conhecimento profissional. Trata-se, de acordo com Imbernón (2001), de um conhecimento dinâmico e não-estático que se desenvolve ao longo da carreira profissional, em diversos momentos: na experiência como discente, quando, ainda como aluno, o professor transita pelo sistema educativo e assume uma determinada visão da educação, marcada, por vezes, por estereótipos e imagens da docência difíceis de serem superados; na etapa de formação inicial, que deveria ter um papel decisivo não apenas na promoção do conhecimento profissional, mas de todos os aspectos da profissão docente, promovendo as primeiras eventuais mudanças na forma de o futuro professor encarar atitudes, valores e funções relativas à docência; na vivência profissional imediatamente posterior no campo da prática educacional, que leva à consolidação de um determinado conhecimento profissional (assumindo-se esquemas, pautas e rotinas da profissão); na formação permanente, que tem como uma de suas funções questionar ou legitimar o conhecimento profissional posto em prática.

Diferentes fases foram descritas por Huberman (1993) ao analisar o ciclo de vida profissional de professores, confrontando dados obtidos em suas investigações com a literatura referente ao ciclo de vida humano e com a escassa literatura direcionada, mais especificamente, ao estudo da carreira profissional docente. O pesquisador focalizou a trajetória profissional de professores do ensino secundário, que lecionavam para alunos com idade entre 13 e 19 anos, tendo entre 5 e 40 anos de experiência na profissão, com diferentes vivências institucionais, responsáveis por diferentes disciplinas. Sem desconsiderar que o desenvolvimento profissional docente deve ser descrito muito mais como um processo do que como uma série sucessiva de eventos pontuais, Huberman (1993) descreve fases na carreira docente e demonstra que elas são constantemente vivenciadas pelos professores, embora faça questão de destacar que o fato de que seqüências possam ser estabelecidas na descrição da carreira docente não significa que não existam professores que nunca parem de explorar, que jamais alcancem a estabilidade na profissão, que se desestabilizem, a qualquer momento, por razões diversas e imprevistas.

Dentre tais fases descritas por Huberman (1993) - entrada na carreira, fase de estabilização, fase de experimentação ou diversificação, fase de procura de uma situação profissional estável, fase de preparação da jubilação -, a primeira delas se refere a um período de sobrevivência e descoberta. $\mathrm{O}$ aspecto de sobrevivência tem a ver com o "choque de realidade", com o embate inicial com a complexidade e a imprevisibilidade que caracterizam a sala de aula, com a discrepância entre os ideais educacionais e a vida cotidiana nas classes e escolas, com a fragmentação do trabalho, com a dificuldade em combinar ensino e gestão de sala de aula, com a falta de materiais didáticos, etc. O elemento de descoberta tem a ver com o entusiasmo do iniciante, com o orgulho de ter sua própria classe e fazer parte de um corpo profissional. Sobrevivência e descoberta caminham lado a lado no período de entrada na carreira. Para alguns professores, o entusiasmo inicial torna fácil o começo da docência; para outros, as dificuldades tornam o período muito difícil. 
Marcelo (1998) elabora uma síntese dos principais temas que têm sido abordados nas pesquisas sobre formação de professores, identificando aqueles relativos à pesquisa sobre formação inicial de professores, sobre professores principiantes e sobre desenvolvimento profissional. As pesquisas sobre formação inicial se referem, quase que exclusivamente, aos estágios de ensino e seus efeitos sobre futuros professores. Um outro aspecto bastante estudado se refere às crenças dos professores em formação e às mudanças que nelas são produzidas em conseqüência dos estágios. As pesquisas sobre professor principiante têm procurado caracterizar este período do desenvolvimento profissional docente, centrando-se no estudo do processo de aprender a ensinar durante os primeiros anos de ensino, buscando identificar e analisar problemas e preocupações específicos dos professores que iniciam a carreira, mudanças sofridas pelo professor ao passar de estudante a docente, papel da escola na aprendizagem profissional do iniciante. Pesquisas sobre desenvolvimento profissional analisam processos de mudança vividos pelos professores a partir de dimensões organizacionais, curriculares, didáticas e profissionais, sendo desenvolvidos estudos sobre a dimensão pessoal de tais processos e sobre a aprendizagem dos docentes como pessoas adultas.

Neste artigo, são focalizadas questões relativas ao professor principiante que acaba de adentrar no mundo da profissão docente. Os acontecimentos que marcam as fases iniciais da carreira docente adquirem importância fundamental nos processos de aprendizagem profissional. Tardif e Raymond (2000) apontam que, entre professores que possuem um emprego estável no ensino, as bases dos saberes profissionais parecem ter sido construídas nos anos iniciais da docência. O início na carreira representa, segundo eles, uma fase crítica em relação às experiências anteriores e aos ajustes a serem feitos em função da realidade do trabalho e do confronto inicial com a dura e complexa realidade do exercício da profissão. É um período marcado, em geral, pela desilusão e pelo desencanto e que corresponde à transição da vida de estudante para a vida mais exigente do trabalho. Os primeiros anos de profissão são decisivos na estruturação da prática profissional e podem ocasionar o estabelecimento de rotinas e certezas cristalizadas sobre a atividade de ensino que acompanharão o professor ao longo de sua carreira. De acordo com Feiman-Nemser (2001), os primeiros anos da profissão representam um período intenso de aprendizagens e influenciam não apenas a permanência do professor na carreira, mas também o tipo de professor que o iniciante virá a ser. Marcelo Garcia (1999) descreve o período de iniciação na docência como o período de tempo que compreende os primeiros anos nos quais os professores precisam realizar a transição de estudantes a docentes. Trata-se de uma etapa de tensões e aprendizagens intensivas em contextos geralmente desconhecidos, durante a qual os principiantes devem adquirir conhecimento profissional, além de conseguir manter certo equilíbrio pessoal. Destacam-se como características desse período a insegurança e a falta de confiança em si mesmos de que padecem os professores iniciantes.

Esteve Zaragoza (1999), ao analisar o mal-estar docente que acomete grande parte dos professores nos dias atuais e os mecanismos pelos quais ele é produzido, discute alguns trabalhos que coincidem em suas conclusões a respeito das dificuldades vividas pelo professor iniciante para adaptar a imagem ideal que possui sobre sua profissão às carências e contradições que encontra na instituição educativa concreta em que começa a trabalhar. O professor iniciante se vê desarmado e desconcertado ao perceber que a prática real do ensino não corresponde aos esquemas ideais com os quais ele foi formado. Tais trabalhos apontam que, assim que começa a lecionar, o novo professor inicia uma revisão de suas atividades e ideais, na tentativa de adaptá-los à dura realidade da sala de aula, marcada por uma série de limitações que atuam diretamente sobre seu trabalho, dentre as quais a falta de recursos materiais e condições adequadas de trabalho, o acúmulo de exigências, o aumento da violência nas instituições escolares.

De acordo com Tardif e Raymond (2000), o confronto com a realidade força os professores novatos a questionar a visão idealista que possuem sobre a profissão docente. Distanciados dos conhecimentos acadêmicos e mergulhados no exercício da profissão, passam a reajustar suas expectativas e percepções anteriores. Esteve Zaragoza (1999, p. 44-45) recorre ao estudo desenvolvido por Abraham (1975 apud Esteve Zaragoza, 1999) que classifica, em 
quatro grupos, as diversas reações/atitudes dos professores principiantes ao se defrontarem com uma prática do magistério bastante distante dos ideais pedagógicos assimilados durante a formação inicial:

1. O predomínio de sentimentos contraditórios, sem conseguir esquemas de atuação prática que resolvam o conflito entre ideais e realidade. O professor vai adotar uma conduta flutuante em sua prática docente e em sua valorização de si mesmo.

2. A negação da realidade por sua incapacidade de suportar a ansiedade. O professor vai recorrer a diversos mecanismos de fuga; entre eles, os de inibição e rotinização de sua prática docente são os mais freqüentemente utilizados como meio de cortar a implicação pessoal no magistério.

3. O predomínio da ansiedade, quando o professor se dá conta de que carece dos recursos adequados para pôr em prática seus ideais e, ao mesmo tempo, manter o desejo de não renunciar a eles e de não cortar sua implicação pessoal no magistério. A contínua comparação entre sua pobre prática pedagógica e os ideais que desejaria alcançar o levarão a esquemas de ansiedade quando o professor reage de forma hiperativa, querendo compensar com seu esforço pessoal os males endêmicos do magistério. As manifestações depressivas aparecem nesse mesmo esquema, quando, na comparação, o professor chega à autodepreciação, culpando-se pessoalmente por sua incapacidade de chegar à prática dos ideais pedagógicos aprendidos.

4. A aceitação do conflito como uma realidade objetiva, sem maior importância que a de buscar respostas adequadas nos limites de uma conduta integrada.

Se alguns professores acabam conseguindo manter um certo equilíbrio na profissão, outros se mantêm nela reduzindo sua eficácia e renunciando a um ensino de qualidade, escondendo-se atrás de mecanismos de fuga. Outros, ainda, vivenciam a docência com uma postura contraditória, adotando, em suas práticas escolares, modelos de atuação que não consideram válidos. Alguns professores acabam por ser pessoalmente atingidos pelas dificuldades no confronto com a prática, mantendo-se na profissão à custa de constantes pedidos de transferência e de muitas faltas ao trabalho; vivem acometidos por doenças mais ou menos fingidas, para abandonar momentaneamente a docência, e, por fim, por doenças reais, como depressões mais ou menos graves (Esteve Zaragoza, 1999).

Ao analisar a história de vida de uma professora, buscando compreender os processos de construção/desconstrução de sua identidade profissional, ou seja, tentando captar o movimento de constituição de sua identidade docente ao longo da trajetória profissional e pessoal, e considerando a escola - suas condições materiais e institucionais - como a esfera mais imediata da determinação da prática docente, Caldeira (2000, p. 9) descreve o período de inserção e iniciação dessa professora na profissão como "uma caminhada de enfrentamentos e conflitos diante dos desafios resultantes de sua não-conformação ao conjunto de padrões cristalizados de comportamento docente, presentes nas instituições onde desenvolveu seu trabalho".

A partir de pesquisa realizada com professoras iniciantes, Guarnieri (1996) busca identificar elementos que contribuam para a compreensão dos processos de "aprender a ensinar". Ao examinar, por meio de estudo exploratório e de estudo de caso, o que ocorre com professoras ao iniciar sua carreira docente, focalizando o que pensam, o que sentem, como avaliam sua inserção nas escolas, Guarnieri (2000) destaca alguns aspectos que remetem aos estudos realizados por Esteve Zaragoza (1999). Segundo ela, é possível identificar alterações nos ideais sobre a profissão construídos pelas iniciantes durante a formação inicial e o processo anterior de escolarização, quando deparam com a cultura escolar, com as condições adversas de seu ambiente de trabalho, permeado por relações hierárquicas e burocráticas que dificultam a partilha de dificuldades, dúvidas e problemas. Também é possível constatar dificuldades das professoras iniciantes em lidar com situações relativas ao ensino na sala de aula. Os resultados de seu estudo (Guarnieri, 2000) sugerem que as principiantes não sabem selecionar, organizar, 
priorizar os conteúdos a serem ensinados, escolher procedimentos para transmitir a matéria, selecionar atividades para os alunos, avaliar a classe, cuidar da organização e correção dos cadernos dos alunos, trabalhar com alunos que apresentam dificuldade para aprender, usar a lousa corretamente, distribuir durante um dia de aula os diferentes componentes curriculares. Tais dificuldades indicam que há aspectos do trabalho do professor que parecem ser melhor percebidos pelas principiantes somente a partir da atuação, não sendo focalizados durante a formação inicial.

Ao investigar diferentes fatores que facilitam e/ou dificultam a ação pedagógica de jovens professores, concluintes ou já habilitados pelo curso de formação para o magistério em nível médio, com até cinco anos na função docente, Castro (1995) destaca a imagem negativa que os professores iniciantes entrevistados construíram sobre os anos iniciais de seu percurso profissional, resultante das situações de isolamento, da falta de condições de trabalho e de apoio técnico-pedagógico compatíveis com as dificuldades da prática. Entretanto, também destaca o fato de que o confronto inicial com as situações escolares - marcado pelas dificuldades de adaptação pessoal e profissional, pela insegurança e despreparo, por certas dificuldades em lidar com situações específicas da prática, pelo isolamento, pela ausência de comunicação entre os próprios colegas de profissão e de apoio na busca de solução para os problemas e imprevistos da rotina escolar - não levou os professores investigados a desistirem de investir na carreira docente. Ao contrário, conforme afirma Castro (1995), os professores buscaram estabelecer um equilíbrio em suas carreiras, enfrentaram os primeiros obstáculos, valendo-se deles para reforçar a descoberta de novos caminhos, refletindo sobre os problemas vividos e procurando reavaliar-se a cada momento. Castro (1995) destaca que, mesmo apontando as mais variadas dificuldades na prática, tanto professores mais experientes quanto menos experientes (dentre os iniciantes) demonstraram boa vontade, entusiasmo, expectativa de mudanças em relação à ação pedagógica e uma constante procura de novas informações, além de apresentarem uma forte predisposição de luta e persistência, na busca de um modelo profissional considerado "bom" ou "eficaz".
Assim como no estudo de Guarnieri (1996), na investigação desenvolvida por Castro (1995) pretendeu-se analisar percepções dos professores iniciantes a respeito das principais dificuldades encontradas no exercício da docência. É possível observar, ao comparar resultados de ambos os estudos, que as dificuldades explicitadas se assemelham em diversos aspectos. De acordo com Castro (1995), ao serem abordadas sobre as principais dificuldades encontradas ao ensinar, as professoras iniciantes destacam aquelas referentes a lidar com crianças que apresentam dificuldades de aprendizagem ocasionadas por problemas emocionais, intelectuais ou sociais. Destacam, ainda, dificuldades quanto ao domínio de classe - diante da heterogeneidade que caracteriza as turmas de alunos - e de conteúdo, declarando achar difícil desenvolver conceitos (principalmente matemáticos) que envolvam conhecimentos que não possuem. Castro (1995) afirma que as iniciantes atribuem diferentes causas às dificuldades enfrentadas na prática, destacando a falta de domínio de conteúdos teóricos, principalmente os relativos à Psicologia e à Didática, e a desarticulação entre os conhecimentos teóricos adquiridos na formação inicial e a prática encontrada nas escolas. Para as iniciantes, a falta de domínio de conhecimentos teóricos e a falta de relação entre tais conhecimentos e a prática cotidiana geram insegurança no enfrentamento de diferentes situações de ensino, despreparo para criar ou improvisar atividades estimuladoras aos alunos com dificuldades de aprendizagem e desinformação sobre conteúdos e metodologias específicos da educação infantil e da educação inclusiva.

A falta de conhecimento sobre quais critérios utilizar para selecionar os conteúdos que irão ensinar e, mais que isso, a dificuldade em perceber qual a maneira mais adequada de ensinar determinado conteúdo a um grupo específico de alunos também caracterizam o grupo de professores iniciantes entrevistados por Marcelo Garcia (1992). Alguns desses professores possuem, ainda, dificuldades em transformar os conhecimentos que possuem, como especialistas, em conteúdos de ensino.

Ao investigar o processo de socialização profissional de professores iniciantes, Freitas (2000) constata, assim como outros 
investigadores (Caldeira, 1995; Castro, 1995; Fontana, 2000; Guarnieri, 1996), que tais professores, apesar das dificuldades enfrentadas no início da carreira, tentam, de todas as formas, permanecer nela e realizar um bom trabalho, embora nem sempre sejam bem-sucedidos. O gosto de educar crianças e jovens, a vontade de contribuir para o desenvolvimento da sociedade e a constatação de que a profissão admite autonomia de pensamento e de ação a quem a desempenha são motivações para que o professor iniciante continue a investir na carreira, tão relevantes, ou mais, que a necessidade de obter um salário (Castro, 1995). Nesse sentido, Freitas (2000, p. 91) constata que a vontade de acertar e de ser reconhecido, aliada ao compromisso com os alunos, levam os iniciantes a resistir às dificuldades, pois abandonar a profissão representaria, mais que a perda do emprego, a abdicação de seus projetos pessoais e o desmoronamento de sua identidade profissional. Vale destacar, entretanto, dados americanos levantados por Gold (1996 apud Tardif, Raymond, 2000), segundo os quais $33 \%$ dos iniciantes, durante as fases iniciais da docência, abandonam a profissão ou, ao menos, questionam-se sobre sua escolha profissional e sobre a continuidade da carreira.

Freitas (2000) assinala o fato de que é comum nas escolas pesquisadas a atribuição, aos professores iniciantes, de turmas de alunos consideradas por profissionais que atuam nas escolas como as mais difíceis - por possuírem alunos com grande variação nos níveis de aprendizagem e que, muitas vezes, não possuem materiais escolares mínimos e vêm de famílias caracterizadas pelo baixo poder aquisitivo - e/ou, ainda, de classes situadas nas zonas rurais, onde as condições de trabalho são piores do que nas escolas de zona urbana no que diz respeito à falta de material didático, pouca possibilidade de troca de experiência e acompanhamento pedagógico, delegação de turmas multisseriadas, dificuldade para se conciliar vida profissional e vida pessoal. O professor iniciante é "presenteado" com as piores turmas, os piores horários e as piores condições de trabalho, já que os professores experientes são os primeiros a escolher suas aulas no momento de atribuição das classes (Esteve Zaragoza, 1999).

Freitas (2000) analisa tal situação como perversa - quase como uma utilização instrumental do iniciante para realizar aquele trabalho difícil e que não oferece reconhecimento -, mas destaca, entretanto, que a característica peculiar ao professor iniciante de encarar os problemas que ocorrem nas aulas como apenas seus acaba por reverter essa situação, que parece perversa, em um fator que contribui para sua socialização profissional; o principiante acaba, segundo ele, lutando com todas as suas forças para superar as dificuldades que encontra e desenvolver estratégias que garantam uma melhor atuação. $\mathrm{Na}$ busca de soluções para enfrentar os problemas da prática, acaba construindo saberes e, com o tempo, acaba adquirindo uma segurança maior, uma confiança em si mesmo que extrapola do domínio pessoal para o relacional, passando a ser respeitado pelos demais professores e profissionais da escola.

Com o passar do tempo, conforme evolui na carreira docente e enfrenta os acontecimentos que marcam sua trajetória nas escolas onde atua e nas classes em que leciona, grande parte dos professores iniciantes desenvolve maior segurança e domínio sobre seu trabalho cotidiano e sobre as situações em que transcorre, passando a sentir-se mais confortável diante das exigências da profissão e da tarefa de ensinar (Tardif, Raymond, 2000). De acordo com Freitas (2000), a maior parte desses professores deseja permanecer na profissão, além de conseguir estabilidade e reconhecimento profissional.

Diante do que a literatura tem mostrado em relação aos professores que iniciam na profissão docente - dificuldades, preocupações, sentimentos e aprendizagens -, parece evidente a necessidade de que, especialmente nos primeiros anos da profissão, os professores tenham oportunidades para conversar com outros colegas a respeito do ensino que estão desenvolvendo, das estratégias de aprendizagem de seus alunos, dos problemas para ensinar e das alternativas de atuação (Feiman-Nemser, 2001).

Mizukami et al. (2002) destacam o fato, embora não se refiram especificamente ao professor iniciante, de que os professores precisam fazer parte de uma comunidade de aprendizagem - trabalhando com os pares, recebendo apoio e assessoria de um diretor que compreenda as necessidades colocadas pelas políticas públicas em relação ao papel do professor e às necessidades de mudanças de 
práticas pedagógicas, discutindo suas práticas escolares com outros profissionais que possam oferecer sugestões - que constitua fonte de apoio e de idéias.

\section{Estudos sobre conhecimentos profissionais de professores iniciantes}

Apesar de todas as adversidades que caracterizam o início na docência, o professor iniciante busca cumprir sua tarefa principal: ensinar. Como se dá esse ensino? Com base em quais conhecimentos se desenvolve? Como são construídos e organizados tais conhecimentos? Quais as fontes de tais conhecimentos? Estudos acerca dos conhecimentos que professores iniciantes possuem sobre conteúdos específicos que ensinam e em torno das formas pelas quais eles transformam esse conhecimento em um ensino que promova compreensão nos alunos vêm sendo desenvolvidos (Grossman, Richert, 1988; McDiarmid, Ball, Anderson, 1989; Wilson, Shulman, Richert, 1987). Tais estudos destacam o fato de que, mesmo preocupados em enfrentar as dificuldades iniciais da profissão, os principiantes efetivamente se preocupam com o ensino de conhecimentos a seus alunos. Diante das transformações que caracterizam a sociedade atual, o domínio de conteúdos e de habilidades cognitivas superiores - análise, síntese, estabelecimento de relações, interpretação e uso de diferentes linguagens necessárias para a constante busca da informação e do conhecimento - torna-se imprescindível. O ensino de conteúdos representa tarefa mais ampla que transmitir informações; trata-se de garantir aos alunos acesso aos conhecimentos que lhes permitam participar da vida social e produtiva e aprendizagens que possibilitem buscar, selecionar, produzir, analisar e utilizar tais conhecimentos diante da complexidade e diversidade das situações atuais.

O conhecimento do conteúdo específico ocupa um lugar central na base de conhecimento para o ensino, influenciando tanto o que os professores ensinam como a forma como ensinam (Grossman, Wilson, Shulman, 1989). Durante o planejamento e o decorrer das aulas, o conhecimento que o professor possui do conteúdo específico é enriquecido por outros tipos de conhecimento - dos alunos, do currículo, do contexto (Wilson, Shulman, Richert, 1987). Entretanto, a capacidade dos professores para propor questões, selecionar atividades, avaliar o entendimento dos alunos e tomar decisões sobre como ensinar depende de como entendem os conteúdos que ensinam (McDiarmid, Ball, Anderson, 1989).

Ao investigar a base de conhecimento profissional para o ensino - entendida como um conjunto de compreensões, conhecimentos, habilidades e disposições que um professor necessita para transformar o que sabe sobre o conteúdo em formas de atuação que sejam pedagogicamente eficazes e adaptáveis às variações de habilidades e de repertórios apresentados pelos aluno (Mizukami, 2000) -, Shulman (1989) identificou conhecimentos que a fundamentam: conhecimento pedagógico geral (relativo às teorias e princípios de ensino e aprendizagem, aos alunos, ao manejo de classe e à instituição em que trabalha), conhecimento de conteúdo específico (conceitos e idéias de uma área de conhecimento; formas de construção de conhecimentos em determinada área) e conhecimento pedagógico do conteúdo.

Representando uma combinação entre o que sabe sobre a matéria e sobre o modo de ensiná-la, o conhecimento pedagógico do conteúdo é apontado como um novo tipo de conhecimento da área que é desenvolvido pelo professor, ao tentar ensinar um tópico em particular a seus alunos. É novo porque é revisto e melhorado pelo docente - que lança mão de outros tipos de conhecimento - para que possa ser realmente compreendido pelas crianças. Pressupõe uma elaboração pessoal do professor ao confrontar-se com o processo de transformar em ensino o conteúdo aprendido durante seu processo formativo, incorporando, de acordo com Shulman (1986, p. 9):

[...] aspectos do conteúdo mais relevantes para serem ensinados. Dentro da categoria de conhecimento pedagógico do conteúdo, incluo, para a maioria dos tópicos regularmente ensinados de uma área específica de conhecimento, as representações mais úteis de tais idéias, as analogias mais poderosas, ilustrações, exemplos, explanações e demonstrações - em outras palavras, os modos de representar e 
formular o conteúdo que o tornam compreensível para os outros. Conhecimento pedagógico do conteúdo também inclui uma compreensão do que torna a aprendizagem de tópicos específicos fácil ou difícil: as concepções e preconcepções que estudantes de diferentes idades e repertórios trazem para as situações de aprendizagem dos conteúdos e lições freqüentemente ensinados.

Diante das preocupações em torno dos conhecimentos profissionais docentes, estudos sobre conhecimento pedagógico do conteúdo se configuram como uma das contribuições mais poderosas e atuais da investigação sobre formação de professores; trata-se do tipo de conhecimento específico da profissão docente, imprescindível ao desenvolvimento de um ensino que propicie a compreensão, a construção e a elaboração de conhecimentos pelos alunos (Marcelo Garcia, 1992). Evidencia-se na tentativa dos professores de encontrar as melhores formas para representar suas idéias aos estudantes considerando suas possibilidades de compreensão - e na construção de metáforas, analogias, simulações, representações visuais, modelos e de um conjunto de outros tipos de representações que objetivam comunicar aos alunos aspectos dos conteúdos específicos a serem ensinados. Ao analisar situações em que professores tentam ensinar conteúdos específicos, de diferentes naturezas, a seus alunos, investigações têm trazido importantes elementos para discussões sobre os conhecimentos que fundamentam o ensino e os processos pelos quais ele se desenvolve.

O processo em que professores transformam conhecimento em ensino, a partir de uma base de conhecimento profissional, é denominado por Wilson, Shulman e Richert (1987) como processo de raciocínio pedagógico. Tal processo, conforme descrito pelos pesquisadores, envolve seis aspectos comuns ao ato de ensinar: compreensão, transformação, instrução, avaliação, reflexão e nova compreensão.

O raciocínio pedagógico se inicia com a compreensão de idéias e conceitos de um mesmo conteúdo e conteúdos relacionados, com o entendimento das estruturas e princípios que fundamentam as disciplinas e a construção dos conteúdos que a constituem. Envolve, ainda, um processo de transformação, constituído pela interpretação (revisão dos materiais instrucionais a partir do próprio entendimento do conteúdo específico); representação (conjunto de metáforas, analogias, ilustrações, atividades, exemplos, etc., que o professor possa utilizar para transformar o conteúdo em ensino); adaptação (ajuste da transformação às características dos alunos em geral); consideração dos alunos específicos aos quais deve ensinar determinado conteúdo. A instrução consiste em aspectos observáveis do comportamento do professor, como manejo de classe, explicações, questionamentos, discussões, etc. A avaliação ocorre durante e depois da instrução; refere-se à checagem da compreensão ou não dos estudantes em relação ao que foi ensinado. Além disso, os professores avaliam seu próprio ensino através do processo de reflexão, que representa o processo de aprendizagem a partir da experiência; é o momento em que o professor revê seu ensino, reconstituindo eventos, emoções, acontecimentos. Finalmente, o raciocínio pedagógico envolve nova compreensão que é enriquecida, aperfeiçoada; nem sempre vista após cada tópico ensinado, pode se desenvolver lentamente, com o decorrer das vivências, ou pode surgir a partir de alguma situação com características singulares.

Estudos desenvolvidos por Tardif, Lessard e Lahaye (1991) e Tardif (2002) trouxeram elementos importantes relativos à natureza e às fontes dos saberes profissionais dos professores. Alguns aspectos do trabalho docente, não focalizados nos estudos da base de conhecimento para o ensino e dos processos de raciocínio pedagógico, aparecem nas considerações feitas por estes pesquisadores em relação aos saberes docentes e esclarecem questões relativas às origens destes saberes. Se a tipologia dos conhecimentos profissionais docentes elaborada por Shulman (1986) permite discriminar os diferentes tipos de conhecimentos que fundamentam o trabalho dos professores e analisar processos pelos quais são mobilizados e construídos durante a atividade de ensinar diferentes matérias aos alunos, a tipologia desenvolvida por Tardif, Lessard e Lahaye (1991) evidencia as fontes de aquisição dos saberes docentes, relacionando-os com seus modos de integração no trabalho do professor. 
O quadro a seguir (Tardif, 2002, p. 63) apresenta tal tipologia:

\begin{tabular}{|l|l|l|}
\hline \multicolumn{1}{|c|}{ Saberes dos professores } & Fontes sociais de aquisição & \multicolumn{1}{|c|}{$\begin{array}{c}\text { Modos de integração } \\
\text { no trabalho docente }\end{array}$} \\
\hline $\begin{array}{l}\text { Saberes pessoais dos } \\
\text { professores. }\end{array}$ & $\begin{array}{l}\text { A família, o ambiente de vida, } \\
\text { a educação no sentido lato. }\end{array}$ & $\begin{array}{l}\text { Pela história de vida e pela } \\
\text { socialização primária. }\end{array}$ \\
\hline $\begin{array}{l}\text { Saberes provenientes da } \\
\text { formação escolar anterior. }\end{array}$ & $\begin{array}{l}\text { A escola primária e secun- } \\
\text { dária, os estudos pós- } \\
\text { secundários não } \\
\text { especializados. }\end{array}$ & $\begin{array}{l}\text { Pela formação e pela sociali- } \\
\text { zação pré-profissionais. }\end{array}$ \\
\hline $\begin{array}{l}\text { Saberes provenientes da } \\
\text { formação profissional para o } \\
\text { magistério. }\end{array}$ & $\begin{array}{l}\text { Os estabelecimentos de } \\
\text { formação de professores, os } \\
\text { estágios, os cursos de } \\
\text { reciclagem. }\end{array}$ & $\begin{array}{l}\text { Pela formação e pela sociali- } \\
\text { zação profissionais nas } \\
\text { instituições de formação de } \\
\text { professores. }\end{array}$ \\
\hline $\begin{array}{l}\text { Saberes provenientes dos } \\
\text { programas e livros didáticos } \\
\text { usados no trabalho. }\end{array}$ & $\begin{array}{l}\text { A utilização das “ferramen- } \\
\text { tas” dos professores: progra- } \\
\text { mas, livros didáticos, } \\
\text { cadernos de exercício, } \\
\text { fichas. }\end{array}$ & $\begin{array}{l}\text { Pela utilização das “ferra- } \\
\text { mentas" de trabalho, sua } \\
\text { adaptação às tarefas. }\end{array}$ \\
\hline $\begin{array}{l}\text { Saberes provenientes de sua } \\
\text { própria experiência na } \\
\text { profissão, na sala de aula e } \\
\text { na escola. }\end{array}$ & $\begin{array}{l}\text { A prática do ofício na escola } \\
\text { e na sala de aula, a experiên- } \\
\text { cia dos pares. }\end{array}$ & $\begin{array}{l}\text { Pela prática do trabalho e pela } \\
\text { socialização profissional. }\end{array}$ \\
\hline
\end{tabular}

\section{Aspectos gerais da pesquisa}

Neste artigo, são apresentados resultados obtidos em pesquisa que objetivou investigar processos de formação vividos por professoras em início de carreira (Nono, 2005). Participaram do estudo quatro professoras iniciantes da educação infantil e dos anos iniciais do ensino fundamental, ${ }^{1}$ com trajetórias diversificadas de entrada na carreira docente, que, no período de coleta de dados (entre 2003 e 2004), possuíam entre dois e cinco anos de profissão.

As professoras analisaram individualmente cinco casos de ensino, ${ }^{2}$ a partir de roteiros de questões abertas, e elaboraram um caso a partir de situações escolares vividas nos anos iniciais da docência. Focos de análise dos dados coletados foram estabelecidos tendo em vista os objetivos da investigação, sendo focalizados diferentes conhecimentos profissionais das professoras iniciantes e processos pelos quais tais conhecimentos foram construídos, organizados e mobilizados por elas no início da carreira docente.

De modo geral, as estratégias de análise e elaboração de casos de ensino possibilitaram descrições e análises das trajetórias profissionais pelas professoras, permitindo também que fossem evidenciadas dúvidas, certezas, equívocos e contradições que orientam e caracterizam suas práticas profissionais. Garantiram, ainda, que conhecimentos referentes ao modo como ensinam conteúdos matemáticos e de linguagem escrita fossem explicitados pelas iniciantes.

Casos de ensino (Merseth, 1996; Mizukami, 2000, 2002; Nono, 2001; Nono, Mizukami, 2004; Shulman, 1992) são narrativas que documentam eventos escolares e que trazem detalhes suficientes para que tais eventos sejam analisados e interpretados a partir de diferentes perspectivas. São narrativas que permitem o acesso aos conhecimentos sobre ensino envolvidos nos eventos descritos. Casos vêm sendo apontados como importantes instrumentos a serem utilizados na investigação e no desenvolvimento da base de conhecimento para o ensino e do processo de raciocínio pedagógico. Ao garantir o acesso - tanto aos investigadores quanto aos próprios professores - aos conhecimentos que fundamentam a atuação docente, os casos sugerem sua importância na estruturação de atividades de formação que considerem os conhecimentos

\footnotetext{
As professoras serão chamadas de Fabiana, Joana, Daniela e Mariana, nomes fictícios.

${ }^{2}$ Os casos de ensino utilizados foram: "A trajetória profissional de Stefânia, professora de Educação Infantil" (Padilha, 2002); "Um dinheiro, dois dinheiros, três dinheiros..." (Toledo, 1999): "Escreva do seu jeito" (Aratangy, 2002); "A Gata Borralheira, a Cinderela e o Sapatinho Dourado" (Abreu, 2002): "Produzindo textos" (Abreu, 2002a).
} 
profissionais dos professores e que permitam seu desenvolvimento.

Além disso, a importância dos casos de ensino aumenta quando se considera que os processos de aprender a ensinar ocorrem na interação do professor com o contexto no qual leciona. Situações específicas são fundamentais nos processos de construção dos conhecimentos profissionais docentes. Ao apresentarem situações escolares singulares, os casos de ensino possibilitam a análise de questões estritamente relacionadas ao contexto escolar e de sala de aula - que envolvam as implicações sociais, econômicas e políticas da atividade de ensinar - e, ainda, permitem que professores, conjuntamente, discutam e analisem tais situações, refletindo sobre conhecimentos profissionais próprios da docência que lhes possibilitam transformar conhecimentos que ensinam de modo que os alunos possam aprendê-los.

$\mathrm{Na}$ investigação que fundamenta este artigo (Nono, 2005), casos de ensino foram utilizados como ferramentas formativas e investigativas, revelando-se importantes instrumentos para promoção e investigação dos processos formativos vividos pelas professoras em início de carreira. ${ }^{3}$

Em relação às professoras participantes da pesquisa, é possível caracterizá-las, antes de mais nada, em relação ao tempo de experiência docente e à formação para a docência recebida. Fabiana possuía, no período 2003-2004, aproximadamente quatro anos de experiência docente em escola particular, trabalhando, desde 1999, com crianças de 1-2 anos de idade, na educação infantil, e, também, com crianças de 4-5 anos; concluiu o curso de Pedagogia e freqüentava especialização em Psicopedagogia. A professora Daniela possuía, durante o período de coleta de dados (2003-2004), aproximadamente três anos de experiência docente, tendo iniciado sua carreira em 2001, trabalhando em uma turma de $1^{\text {a }}$ série do ensino fundamental, em escola particular, inicialmente como professora-auxiliar e, logo em seguida, como professorasubstituta da titular, que esteve em licença-maternidade. Em 2003, lecionava na educação infantil, numa turma com crianças de 6 anos de idade, na mesma escola particular e, também, em escola pública estadual, em classes de reforço escolar, com um grupo de crianças do $1^{\circ}$ ao $3^{\circ}$ ano do ensino fundamental que estavam sendo alfabetizadas e com um grupo de crianças de $3^{\circ}$ e $4^{\circ}$ anos que estavam aprendendo a produzir textos. No ano de 2004, Daniela foi contratada por uma creche inaugurada em um dos distritos do município de Jaú/ SP para trabalho em tempo integral na educação infantil. Concluiu o curso de Pedagogia e cursava, durante a coleta de dados, especialização em Psicopedagogia. A professora Mariana, com aproximadamente cinco anos de experiência docente, formada também em Letras, concursada pela Prefeitura Municipal de Jaú/SP, lecionava, em 2003, numa turma de $4^{\circ}$ ano do ensino fundamental e numa pré-escola (5-6 anos) e, em 2004, numa pré-escola (5-6 anos) e na disciplina Inglês nos anos finais do ensino fundamental, em escola municipal. Mariana se preparava para prestar concurso público estadual para lecionar nos anos finais do ensino fundamental e no ensino médio, freqüentando, ainda, um curso de Libras (Língua Brasileira de Sinais) e outro de especialização em Literatura. A professora Joana, com aproximadamente dois anos de carreira, possuía experiência docente em escolas estaduais, onde atuou como professorasubstituta por um ano. Em 2003 lecionava em uma turma de $2^{\text {a }}$ série do ensino fundamental, em escola municipal, com contrato de trabalho anual. Concluiu o curso de Pedagogia. Morando em outra cidade e lecionando em Jaú/SP, Joana passava duas horas de seus dias em viagens de ônibus, ficando impossibilitada, segundo ela, de trabalhar em outro período ou de realizar algum curso relativo à profissão.

\section{Resultados e discussão}

\section{As professoras iniciantes e o ingresso na profissão docente}

A partir dos dados obtidos por meio das estratégias de análise e elaboração de casos de ensino, foi possível constatar que as professoras iniciantes, ao descrever suas trajetórias profissionais e processos formativos, procuram estabelecer relações entre as situações vividas nos anos iniciais da carreira e alguns elementos, tais como escolarização prévia, formação inicial, exigências da prática, escola/ambiente de trabalho, políticas públicas educacionais, conhecimentos fundamentais para enfrentar os primeiros anos de ensino, fontes de aprendizagem profissional, pais e alunos, aprendizagens vividas no início na 
carreira, principais dificuldades, obstáculos, desafios, preocupações, dilemas e interesses encontrados na entrada na carreira.

As iniciantes procuram analisar processos vividos no início na docência, buscando apontar fatores que facilitaram ou dificultaram sua iniciação profissional. Procuram traçar seu próprio perfil profissional, apontando aspectos que proporcionaram sua construção e reconstrução constantes. Embora tenham analisado aspectos comuns em suas trajetórias, a partir dos casos de ensino apresentados, cada professora imprimiu uma marca pessoal em seus registros, mostrando diferenças nas formas de encarar os primeiros anos de profissão.

Nas análises que realizaram, expressaram aspectos marcantes de sua trajetória pessoal, mostrando que, apesar das peculiaridades que caracterizam a entrada na carreira, cada professora vivencia esse momento de forma particular, a partir de conhecimentos que possui sobre a profissão, das relações que estabelece com colegas de trabalho, pais de alunos, alunos, da maneira como ingressa na primeira escola. Assim, verifica-se, nos registros da professora Joana, por exemplo, forte tendência em buscar compreender os sentimentos contraditórios que têm marcado seus primeiros anos de profissão e que a têm impulsionado a desistir. Tal busca conduz a descrição de sua entrada na carreira. Enquanto isso, Mariana, já desprovida deste sentimento de instabilidade na profissão que marca os registros de Joana - por ter estabilidade garantida por aprovação em concurso público -, mostra preocupação em manter um ensino de qualidade ao longo da carreira. Daniela focaliza sua preocupação em como conseguir exercer com autonomia a docência, diante da forte influência que tem sofrido em seus anos como professora de escola particular. Já para Fabiana, a maior preocupação está em como lidar com as crianças pequenas e suas interferências no seu trabalho.

Assim como apontam estudos sobre professores principiantes, anteriormente discutidos, a entrada na carreira parece marcada, nos registros das professoras, por aprendizagens diversas, pelo convívio de sentimentos contraditórios em relação à profissão, pela busca excessiva de superação de obstáculos, por fortes exigências pessoais em relação ao próprio desempenho profissional. Analisados em conjuntos, tais registros mostram diferentes trajetórias de principiantes que passam por um período intenso de descobertas e de tentativa de sobrevivência na profissão (Huberman, 1993) - trajetórias mais fáceis para algumas, muito mais difíceis para outras. Os registros sugerem que, das quatro professoras, três - com 3-5 anos de carreira - sobreviveram às maiores dificuldades, passando a aceitar a ansiedade e os conflitos como característicos da docência e como fontes de aprendizagem profissional, desenvolvendo maior segurança e domínio sobre as situações cotidianas que enfrentam (Tardif, Raymond, 2000). Uma delas, entretanto, com apenas dois anos de carreira, enfrentava um período de quase abandono da profissão, sentindo-se pessoalmente atingida pelas dificuldades no confronto com a prática (Esteve Zaragoza, 1999).

Aspectos comuns nos registros das professoras se referem às formas como encaram os processos de desenvolvimento profissional docente. As principiantes explicitam e discutem o caráter de continuidade da aprendizagem da profissão e a dimensão formativa da escola/ambiente de trabalho. Trechos de seus registros apontam para um reconhecimento de que a formação docente não se encerra no curso de formação inicial, mas continua acontecendo ao longo da carreira, principalmente no próprio ambiente de trabalho do professor, na troca de experiências com os colegas e com os alunos.

Aprendi esses conhecimentos na escola, junto com os alunos (Mariana). Venho aprendendo bastante a cada dia na sala de aula. [...] Acredito que a aprendizagem da profissão docente começa na busca de informação a respeito e não termina nunca, pois a cada momento surgem novos conflitos nos quais temos que parar, buscar novas hipóteses e por em prática tudo que sabemos; dessa forma, estamos sempre aprendendo (Joana). [...] a formação docente nunca se acaba, ela começou quando decidi tornar-me uma professora e não se acabará enquanto o mundo estiver mudando continuamente, junto com o ser humano (Fabiana). Penso que a escola é o espaço principal para a formação do professor. É nela que as discussões sobre a própria realidade aparecem e são refletidas para que haja mudança de comportamentos e atitudes. Acho 
importantíssimo ter uma equipe unida onde pode-se trocar idéias e opiniões, aprendendo com quem tem mais experiência. Daí é que se dá a formação contínua do educador (Daniela).

Aparentemente, as professoras atribuem ao professor um papel ativo em sua aprendizagem da profissão e defendem a criação de espaços coletivos nas escolas para trocas de experiências e construção de novos conhecimentos sobre o ensino, reconhecendo o valor dos saberes profissionais construídos no cotidiano escolar. Vale destacar que, durante o curso de formação inicial, as professoras já apontavam a aprendizagem da profissão docente como um processo contínuo (Nono, 2001). O que não acontecia, naquele momento, era a valorização do ambiente escolar como local de aprendizagem da docência. Aspectos relacionados com a organização escolar e suas possíveis influências no trabalho de sala de aula não eram discutidos pelas futuras professoras ao analisar situações de ensino. A entrada na profissão parece ter propiciado o estabelecimento de relações entre sala de aula e escola.

Ao discutir o significado do curso de formação inicial em seu processo de desenvolvimento profissional, as iniciantes destacam a importância de que ele se caracterize pela articulação entre teoria e prática. O curso de formação inicial é apontado como apenas uma das fontes de aprendizagem profissional docente. Destacam também saberes advindos de sua própria história de vida, de sua escolarização anterior, da sua própria experiência na sala de aula e na escola, de seus estudos teóricos (Tardif, 2002).

\section{As professoras iniciantes e o ensino de conteúdos nos primeiros anos de escolarização}

Os dados obtidos sinalizam lacunas que as professoras iniciantes possuem em algumas áreas do conhecimento que devem ensinar. Algumas dessas lacunas são percebidas por elas, outras não. Permanece sua crença - evidenciada durante o curso de formação inicial (Nono, 2001) - de que o domínio de conteúdos específicos pode ser alcançado durante o exercício da docência, sempre que a prática solicitar.
A disposição para aprender novos conteúdos - demonstrada durante a formação inicial - parece se confirmar. Diante das dificuldades no domínio de um ou outro conteúdo, as professoras declaram: "[tenho] buscado ajuda com alguns professores, peguei alguns livros [...] estou correndo atrás e acredito que venho cumprindo meu papel” (Joana). “[...] Agora tenho corrido atrás dos prejuízos. Me atualizo com os cursos que freqüento, com as capacitações, com os grupos de estudo e nas próprias pesquisas que faço quando é necessário” (Daniela). Trecho escrito pela professora Mariana demonstra sua constatação de que o ideal é aprender os conteúdos no exercício da docência, diante da necessidade: “[...] hoje devido a necessidade e até por interesse, busco informações, leio muito, enfim, me amadureci. Em um contexto anterior não tinha porquê me dedicar a elas [determinadas áreas do conhecimento]”.

Os registros permitiram a constatação de certa preocupação das professoras com a transformação dos conhecimentos que possuem em ensino. Mariana afirma que não tem o que superar em termos de lacunas em uma ou outra área do conhecimento: "[...] só corro atrás da didática de como passar aos alunos". "Acredito que na Matemática tenho uma certa dificuldade para transmitir com clareza alguns conteúdos [...]. Na área de Artes também tenho encontrado certas dificuldades, me faltam, talvez, idéias de atividades [...]”, acrescenta Joana.

Vale destacar, entretanto, que, mesmo a disposição das principiantes para aprender os conteúdos antes de ensiná-los - suprindo assim lacunas da trajetória escolar parece insuficiente quando se desconhece a própria defasagem. Os dados sugerem, por exemplo, que, em muitos momentos, as iniciantes acabam recorrendo aos modelos pedagógicos aos quais foram expostas, apesar de explicitarem sua preocupação em organizar situações de ensino diferentes daquelas que vivenciaram na infância. Equívocos e lacunas nos conhecimentos que devem ensinar parecem interferir na seleção de procedimentos de ensino, na avaliação do entendimento dos alunos, na análise das estratégias de aprendizagem elaboradas pelas crianças, influenciando, portanto, todo o processo de raciocínio pedagógico vivido pelas professoras. Esse processo se inicia com a compreensão de idéias e conceitos dos conteúdos que se quer ensinar e de conteúdos relacionados a eles. 
Falhas nessa compreensão parecem interferir em todos os demais momentos dele.

Ao focalizar, por exemplo, conhecimentos das principiantes sobre conteúdos relativos à Matemática, surgem evidências de que concebem as quatro operações fundamentais (soma, subtração, multiplicação e divisão) como tendo apenas um significado: aquele ensinado durante seu processo de escolarização anterior. O fato é que todas as quatro operações têm mais de um significado, ou mais de um uso (Brasil, 1997). Ao desconhecer os diversos significados das operações, acabam recorrendo a práticas de ensino a que foram expostas na infância para ensiná-las. Joana, por exemplo, organiza suas aulas pautada no seguinte roteiro: explicação do conteúdo (recorrendo à apresentação de definições e exemplos), apresentação de exercícios de aplicação do que foi ensinado e correção deles na lousa. Parece não analisar as representações escritas das crianças e suas hipóteses de resolução das situações-problema propostas. Embora acolha as representações das crianças, sua preocupação parece voltada para a aprendizagem da resolução da 'conta armada'. Joana afirma lidar com as estratégias pessoais das crianças, mas, aparentemente, tais estratégias não representam ponto de partida nas situações de ensino que organiza nem são tidas como forma de compreender como os alunos aprendem os conceitos matemáticos.

Daniela, assim como Joana, também explicita sua valorização das explicações prévias nas aulas envolvendo a aprendizagem de conceitos matemáticos, embora descreva, também, aulas centradas nas atividades das crianças e na resolução de situações-problema como desencadeadoras da aprendizagem. Daniela tende a valorizar as ações das crianças em seu aprendizado, criando oportunidades para que pensem, troquem idéias, façam descobertas, utilizem e ampliem seus conhecimentos. Mariana, assim como Joana, também descreve situações em que utiliza situações-problema como forma de aplicação de conceitos anteriormente ensinados, afirmando que "[...] depois que as crianças compreenderem o processo, faria algumas situações-problema, coletivo e individualmente, verificando todo o processo”. Entretanto, também destaca a importância de que os alunos tenham espaço para criar suas estratégias, apresentá-las aos colegas e discuti-las.
Tratando especificamente das formas como as professoras iniciantes encaram e utilizam as estratégias pessoais das crianças no ensino da Matemática - e o modo como avaliam o uso que fazem delas nota-se que, ao desconhecer, elas mesmas, diversas estratégias de resolução de um mesmo algoritmo ou situação-problema, acabam por lidar, algumas vezes, de forma superficial com as hipóteses das crianças, encarando-as muito mais como descobertas e invenções do que como construções dos alunos em seu processo de aprendizagem. Observa-se que Joana chega a se espantar com as estratégias elaboradas pelos alunos. Esta professora, ao refletir sobre seu ensino, avalia positivamente o fato de deixar que as crianças exponham tais estratégias, mas não parece notar que deveria partir delas para organizar seu ensino, na medida em que parece conhecer apenas estratégias convencionais de resolução de problemas.

No que se refere aos conhecimentos das principiantes sobre conteúdos relativos à leitura e à escrita, os dados sugerem que, neles, também estão presentes lacunas que, por vezes, interferem nas formas como as professoras tentam ensinar. Os diversos conhecimentos lingüísticos que devem fundamentar o ensino e a aprendizagem da lecto-escrita - relativos aos aspectos fonológicos, ortográficos, morfossintáticos, semânticos, textuais, discursivos da língua e aos gêneros textuais - não são apontados pelas principiantes como norteadores dos planejamentos de suas aulas.

Foi possível constatar uma disposição das iniciantes para desenvolver práticas escolares pautadas na construção do conhecimento pela criança e na valorização de suas hipóteses sobre a escrita e a leitura. Referem-se, constantemente, aos níveis de aprendizagem e de escrita das crianças, destacando a necessidade de que as professoras consigam identificá-los e considerá-los em seu ensino. Ao analisar uma das situações de ensino propostas, Daniela escreve que "[...] deu pra perceber que, diante da dificuldade encontrada (uns não se contentavam só com as informações da capa, outros já conheciam as letras e arriscavam palpites, outros já tentavam uma leitura silábica, reconhecendo algumas letras), as crianças estão em diferentes níveis: uns pré-silábicos analisando somente imagens, outros silábicos 
e outros até mesmo silábicos alfabéticos". Fabiana destaca que "[...] no início desse trabalho [com alfabetização] não conhecia muito bem os níveis de escrita e, conseqüentemente, não saberia avaliar e trabalhar com as dificuldades das crianças". Avalia seus alunos de 5-6 anos de idade dizendo que "[...] a maioria está no nível silábico com valor sonoro e alguns em transição para o silábico alfabético (Emília Ferreiro)”.

Em algumas análises, entretanto, transparece um uso inadequado e, por vezes confuso, das descobertas em torno dos níveis de escrita das crianças. Mariana assim escreve acerca de seus alunos:

[...] possuem algumas dificuldades, nem sei se deveria chamar assim; estão em um nível em que escrevem palavras simples, utilizando das sílabas; pois ainda estão na fase em que é difícil utilizar M, N, ÃO, AM nas terminações de palavras; mas acho normal. [...] eles sabem pouco sobre leitura, mas acredito que estão em nível correto [...].

Seus relatos demonstram uma tendência a utilizar as pesquisas de Ferreiro (1990) como justificativa para a não-aprendizagem de algumas crianças. Ao analisar, por exemplo, trecho das análises realizadas por Fabiana, nota-se que - apesar de destacar a importância de que a professora identifique a fase de escrita da criança para poder atuar -, ao descrever sua atuação, a avaliação do nível da escrita dos alunos aparece ao final de um conjunto de atividades.

Ao focalizar, portanto, procedimentos metodológicos utilizados pelas iniciantes ao lidar com alfabetização, nota-se que trechos escritos por Mariana sugerem que as atividades de ensino desenvolvidas em classe independem, de certa forma, da consideração do nível de escrita das crianças. Vê-se que ela elenca um rol de atividades que são realizadas cotidianamente. Depoimentos da professora Daniela, por outro lado, sugerem uma utilização mais continuada das hipóteses das crianças para orientar suas intervenções. Nota-se também que, nas análises sobre seu ensino, procura, mais que elencar atividades que desenvolve, tratar de suas concepções sobre funções da escola no ensino da leitura/escrita e sobre como a criança aprende, dos objetivos dos materiais que utiliza na alfabetização, de aspectos que devem ser trabalhados na aquisição da escrita.

Em relação às formas como as iniciantes se referem e utilizam os conhecimentos prévios das crianças relativos ao sistema de escrita, verifica-se que Fabiana e Mariana expressam sua crença de que a aprendizagem da leitura e da escrita da maioria de seus alunos tenha ocorrido estritamente no ambiente escolar, sendo que apenas alguns deles, segundo elas, sofreram interferências do ambiente familiar. Apenas Daniela destaca a importância dos conhecimentos sobre a escrita construídos pelos alunos antes da escolarização, no contato com outros adultos e com material impresso freqüente nos ambientes urbanos. Um dos conhecimentos que a criança já possui ao entrar na escola, segundo ela, diz respeito às funções sociais da escrita. Ao destacar esses conhecimentos quando analisa os processos de aprendizagem de seus alunos, Daniela, ao mesmo tempo, demonstra valorizar as concepções que as crianças construíram fora do ambiente escolar e explicita sua compreensão da escrita como algo mais que um produto escolar.

De modo geral, é possível constatar, tanto no que diz respeito ao ensino de conteúdos relativos à Matemática quanto aos conteúdos relativos à leitura e à escrita, que as professoras iniciantes vivenciam um momento de transição entre a adoção de práticas que parecem valorizar e de práticas semelhantes àquelas a que foram expostas durante seu processo de escolarização. Weisz (2002, p. 58-59) enfatiza que:

Quando se tenta sair de um modelo de aprendizagem empirista para um modelo construtivista, as dificuldades de entendimento às vezes são graves. [...] Se o professor procura inovar sua prática, adotando um modelo de ensino que pressupõe a construção de conhecimento sem compreender suficientemente as questões que lhe dão sustentação, corre o risco, grave no meu modo de ver, de ficar se deslocando de um modelo que lhe é familiar para o outro, meio desconhecido, sem muito domínio de sua própria prática - 'mesclando’, como se costuma dizer. [...] É fácil nos perdermos em nossa prática educativa quando não nos damos conta do que orienta de fato nossas ações. 
Transitando entre uma maneira tradicional de ensinar e uma perspectiva construtivista de encarar o processo de aprendizagem dos alunos, parece fundamental que as iniciantes tenham clareza de como as crianças aprendem e de quais suas possibilidades de ensino.

\section{Considerações finais}

Os dados demonstram forte implicação das professoras principiantes em sua própria aprendizagem profissional da docência e explicitam sua disposição para expor suas formas de atuação, a partir da elaboração e análise de casos de ensino. Retratam as iniciantes como profissionais dispostas a pensar sobre seu ensino, construir conhecimentos durante sua atuação, rever e retomar suas práticas para garantir a aprendizagem das crianças. Mostram que, apesar de iniciantes e de todas as adversidades que caracterizam esse período da carreira, sentem-se capazes de tomar decisões e ter opiniões, transitando para uma fase de estabilização na carreira (Huberman, 1993). Apontam diversos conhecimentos profissionais que mobilizam para desenvolver seu ensino: conhecimento pedagógico geral, conhecimento do conteúdo específico, conhecimento pedagógico do conteúdo. Sendo preenchidas algumas lacunas em seus conhecimentos profissionais - evidenciadas nos dados obtidos -, poderão, cada vez mais, levantar novas dúvidas sobre sua atuação, implicando-se, constantemente, em seus processos de desenvolvimento profissional.

Transparece, nos dados obtidos, a disposição das principiantes para refletir sobre sua prática de ensino e orientar suas intervenções pelas observações e análises que realizam diante da participação das crianças nas aulas que propõem. Confirma-se a necessidade de seu envolvimento em programas de formação continuada que permitam a revisão e a ampliação de seus conhecimentos profissionais.

Para finalizar, vale destacar que, ao caracterizar as professoras iniciantes que participaram desta investigação, foram obtidos resultados semelhantes àqueles encontrados em estudos realizados por Caldeira (1995), Castro (1995), Fontana (2000), Guarnieri (1996). Trata-se de um período de sobrevivência e descoberta, no qual as professoras procuram ajustar suas expectativas e ideais sobre a profissão às condições reais de trabalho que encontram, procurando lidar com uma série de limitações que atuam diretamente sobre seu trabalho, tentando permanecer na profissão e manter um certo equilíbrio diante dos sentimentos contraditórios que marcam a entrada na carreira. Burke (1990 apud Marcelo Garcia, 1999) afirma que a evolução do ciclo vital do professor deve ser entendida em função de duas grandes dimensões: pessoal e organizacional. Do ponto de vista pessoal, existem diversos fatores que influenciam os professores: relações familiares, crises pessoais, etc. O ambiente organizacional influencia a carreira por meio dos estilos de gestão encontrados, das expectativas sociais em relação à profissão, etc. Nos dados obtidos, foram evidenciadas as influências de aspectos pessoais e organizacionais nos processos de formação das professoras iniciantes.

Conforme salienta Huberman (1993), foi possível constatar que essa fase da carreira não é vivenciada exatamente da mesma maneira por todos os professores. As formas como cada professora lida com os aspectos que caracterizam a entrada na profissão podem variar, sendo tal período encarado a partir de diversas perspectivas e conhecimentos anteriores.

Os resultados desta investigação parecem confirmar a necessidade de que sejam organizados programas de iniciação ao ensino para professoras principiantes que respondam “[...] à concepção de que a formação de professores é um contínuo que tem de ser oferecida de um modo adaptado às necessidades de cada momento da carreira profissional" (Marcelo Garcia, 1999, p. 119). Tais programas devem ser compreendidos como um "[...] elo imprescindível que deve unir a formação inicial ao desenvolvimento profissional ao longo da carreira docente”. É necessário que levem em conta diferentes conhecimentos profissionais que orientam as práticas escolares adotadas pelas principiantes e utilizem estratégias diversificadas que promovam processos de desenvolvimento profissional docente.

Neste artigo, procurou-se apontar alguns destes conhecimentos, evidenciados pela utilização de uma das estratégias possíveis de serem utilizadas em tais programas: a análise e elaboração de casos de ensino. Os dados revelam a complexidade que caracteriza os processos de formação 
de professoras em início de carreira e, ao mesmo tempo, evidenciam o potencial dos casos de ensino como estratégias para promover e investigar tais processos.

Objetivou-se, também, neste artigo, sistematizar pesquisas sobre formação de professores principiantes já realizadas.
A produção sobre o tema vem crescendo nos últimos anos, e novas pesquisas têm sido desenvolvidas (Corsi, Lima, 2005; Mariano, 2005; Lima, 2006), o que tem revelado a importância das investigações sobre esse momento peculiar da profissão docente: a entrada na profissão.

\section{Referências bibliográficas}

ABREU, A. R. A Gata Borralheira, a Cinderela e o Sapatinho Dourado. In: WEISZ, T. $O$ diálogo entre o ensino e a aprendizagem. São Paulo: Ática, 2002. p. 25-27.

Produzindo textos. In: WEISZ, T. O diálogo entre o ensino e a aprendizagem. São Paulo: Ática, 2002a. p. 90-91.

ARATANGY, C. Escreva do seu jeito! In: WEISZ, T. O diálogo entre o ensino e a aprendizagem. São Paulo: Ática, 2002. p. 87-89.

BRASIL. Ministério da Educação. Secretaria de Educação Fundamental. Parâmetros curriculares nacionais. Matemática. Brasília: MEC/SEF, 1997.

CALDEIRA, A. M. S. A história de vida como um instrumento para compreensão do processo de construção da identidade docente. In: ENCONTRO NACIONAL DE DIDÁTICA E PRÁTICA DE ENSINO, n. 10, Rio de Janeiro. Ensinar e aprender: sujeitos, saberes, tempos e espaços. Rio de Janeiro, 2000. 1 CD-ROM. Não paginado.

A apropriação e construção do saber docente e a prática cotidiana. Cadernos de pesquisa, São Paulo, Fundação Carlos Chagas/Cortez, n. 95, p. 5-12, 1995.

CASTRO, M. A. C. D. O professor iniciante: acertos e desacertos. 1995. 120 p. Dissertação (Mestrado em Educação) - Pontifícia Universidade Católica de São Paulo, São Paulo, 1995.

CORSI, A. M.; LIMA, E. F. O início da construção da profissão docente: analisando dificuldades enfrentadas por professoras de séries iniciais. In: MIZUKAMI, M. G. N.; REALI, A. M. M. R. Processos formativos da docência. Conteúdos e práticas. São Carlos: EdUFSCar, 2005. p. 163-183.

ESTEVE ZARAGOZA, J. M. O mal-estar docente: a sala de aula e a saúde dos professores. Tradução de D. C. Cavicchia. Bauru: EDUSC, 1999. 175 p.

FEIMAN-NEMSER, S. From preparation to practice: designing a continuum to strengthen and sustain teaching. Teachers College Record, New York, Teachers College, Columbia University, v. 103, n. 6, p. 1013-1055, 2001.

FERREIRO, E. Reflexões sobre alfabetização. 16 ed. São Paulo: Cortez Autores Associados, 1990. 103 p. (Coleção Polêmicas do Nosso Tempo, 17).

FONTANA, R. C. Trabalho e subjetividade. Nos rituais da iniciação, a constituição do ser professora. Cadernos Cedes, Campinas, ano XX, n. 50, p. 103-119, 2000.

FREITAS, M. N. C. O professor iniciante e suas estratégias de socialização profissional. 2000. Dissertação (Mestrado em Educação) - Pontifícia Universidade Católica, FUNREI, Rio de Janeiro, 2000. 
GUARNIERI, M. R. Contribuições da pesquisa centrada na aprendizagem profissional docente. In: ENCONTRO NACIONAL DE DIDÁTICA E PRÁTICA DE ENSINO (ENDIPE), n. 10, Rio de Janeiro. Ensinar e aprender: sujeitos, saberes, tempos e espaços. Rio de Janeiro, 2000. 1 CD-ROM. Não paginado.

Tornando-se professor: o início na carreira docente e a consolidação na profissão. 1996. Tese (Doutorado em Educação) - Universidade Federal de São Carlos, São Carlos, 1996.

GROSSMAN, P. L.; RICHERT, A. E. Unacknowledge knowledge growth: a re-examination of the effects of teacher education. Teaching and Teacher Education, Great Britain, Pergamon Press, v. 4, n.1, 1988.

GROSSMAN, P. L.; WILSON, S. M.; SHULMAN, L. S. Teachers of substance: subject matter knowledge for teaching. In: REYNOLDS, M. C. (Ed.). Knowledge base for beginning teacher. Great Britain: Pergamon Press, 1989. p. 23-34.

HUBERMAN, M. The lives of teachers. New York: Teachers College Press, Columbia University, 1993.

IMBERNÓN, F. Formação docente e profissional: formar-se para a mudança e a incerteza. 2. ed. São Paulo: Cortez, 2001. 119 p. (Coleção Questões da Nossa Época, 77).

LIMA, E. F. (Coord.). Sobrevivências do início da docência: que recados elas nos deixam? Brasília, DF: Liber Livros, 2006.

MARCELO, C. Pesquisa sobre a formação de professores: o conhecimento sobre aprender a ensinar. Revista Brasileira de Educação, n. 9, p. 51-75, 1998.

MARCELO GARCIA, C. Formação de professores: para uma mudança educativa. Porto: Porto Editora, 1999. (Coleção Ciências da Educação - século XXI).

. Como conocen los profesores la materia que enseñan. Algunas contribuiciones de la investigacion sobre conocimiento didactico del contenido. In: CONGRESSO LAS DIDÁCTICAS ESPECÍFICAS EN LA FORMACIÓN DEL PROFESORADO, Santiago, 1992. Disponível em: <http://prometeo.us.es/idea/mie/pub/marcelo>. Acesso em: jan. 2003.

MARIANO, A. L. S. Aprendendo a ser professor no início da carreira: um olhar a partir da ANPEd. REUNIÃO ANUAL DA ASSOCIAÇÃO NACIONAL DE PÓS-GRADUAÇÃO EM EDUCAÇÃO (ANPEd), n. 28, Caxambu, 2005. Disponível em http:www.anped.org.br (GT Formação de Professores).

McDIARMID, W. G.; BALL, D. L.; ANDERSON, C. W. Why staying one chapter ahead doesn't really work: subject-specific pedagogy. In: REYNOLDS, M. C. (Ed.). Knowledge base for the beginning teacher. New York: Pergamon, 1989. p. 193-205.

MERSETH, K. K. Cases and case methods in teacher education. In: SIKULA, J. (Ed.). Handbook of research on teacher education. New York: Macmillan, 1996. p. 722-744.

MIZUKAMI, M. G. N. Formadores de professores, conhecimentos da docência e casos de ensino. In: REALI, A. M. M. R.; MIZUKAMI, M. G. N. (Org.). Formação de professores: práticas pedagógicas e escola. São Carlos: EdUFSCar, Inep, Comped, 2002. p. 151-174.

. Casos de ensino e aprendizagem profissional da docência. In: ABRAMOWICZ, A.; MELLO, R. R. (Org.). Educação: pesquisas e práticas. Campinas: Papirus, 2000. p. 139-161.

MIZUKAMI, M. G. N. et al. Escola e aprendizagem da docência: processos de investigação e formação. São Carlos: EdUFSCar, 2002. 
NONO, M. A. Aprendendo a ensinar: futuras professoras das séries iniciais do ensino fundamental e casos de ensino. 2001. 176 p. Dissertação (Mestrado em Educação) Universidade Federal de São Carlos, São Carlos, 2001.

. Casos de ensino e professoras iniciantes. 2005. 238 p. Tese (Doutorado em Educação) - Universidade Federal de São Carlos, São Carlos, 2005.

NONO, M. A.; MIZUKAMI, M. G. N. Casos de ensino e processos de aprendizagem profissional docente. Revista Brasileira de Estudos Pedagógicos, Brasília, v. 83, n. 203/ 204/205, jan./dez. 2002. Publicada em março de 2004.

Sobre casos de ensino. In: SILVA, A.; ABRAMOWICZ, A.; BITTAR, M. Educação e pesquisa: diferentes percursos, diferentes contextos. São Carlos: RiMa, 2004a. p. 117-137.

PADILHA, S. A trajetória profissional de Stefânia, professora de educação infantil. [jun. 2002]. Vitória Líbia Barreto de Faria. Revista Criança do Professor de Educação Infantil, Brasília, 36, 2002.

SHULMAN, J. H. Case methods in teacher education. New York: Teachers College; London: Columbia University, 1992.

SHULMAN, L. Those who understand: knowledge growth in teaching. Educational Researcher, v. 15, n. 2, p. 4-14, 1986.

Paradigmas y programas de investigación en el estudio de la enseñanza: una perspectiva contemporanea. In: WITTROCK, M. C. (Org.). La investigación de la enseñanza I. Enfoques, teorías y métodos. Barcelona: Paidós, 1989. p. 9-91.

TARDIF, M.; LESSARD, C.; LAHAYE, L. Os professores face ao saber: esboço de uma problemática do saber docente. Teoria e Educação, Porto Alegre, Pannonica, n. 4, p. 215-233, 1991.

TARDIF, M.; RAYMOND, D. Saberes, tempo e aprendizagem do trabalho no magistério. Educação e Sociedade: revista quadrimestral de Ciência da Educação/Centro de Estudos Educação e Sociedade (CEDES), Campinas, n. 73, p. 209-244, 2000.

TARDIF, M. Saberes docentes e formação profissional. Petrópolis: Vozes, 2002.

TOLEDO, M. N. C. Um dinheiro, dois dinheiros, três dinheiros... Revista Criança do professor de Educação Infantil, Brasília, n. 32, p. 30-34, jun. 1999.

WEISZ, T. O diálogo entre o ensino e a aprendizagem. São Paulo: Ática, 2002. p. 25-27.

WILSON, S. M.; SHULMAN, L. S.; RICHERT. A. E. 150 different ways' of knowing: representations of knowledge in teaching. In: CALDERHEAD, J. (Org.). Exploring Teachers' Thinking. London: Cassell Education, 1987. p. 105-123.

Maévi Anabel Nono, doutora em Educação pela Universidade Federal de São Carlos-SP (UFSCar), é docente do Departamento de Educação do Instituto de Biociências, Letras e Ciências Exatas da Universidade Estadual Paulista - Câmpus de São José do Rio Preto (Ibilce/Unesp). Atua em ensino, pesquisa e extensão na área de Formação de Professores.

maevi@ibilce.unesp.br 
Maria da Graça Nicoletti Mizukami, doutora em Ciências Humanas pela Pontifícia Universidade Católica do Rio de Janeiro (PUC-RJ), com pós-doutorado na Santa Clara University/Teacher Education Program, é docente do Programa de Pós-Graduação em Educação da Universidade Federal de São Carlos-SP (UFSCar), área de concentração em Metodologia de Ensino. Atua em ensino (graduação e pós-graduação), pesquisa e extensão na área de Formação de Professores.

gramizuka@gmail.com

Recebido em 15 de maio de 2006.

Aprovado em 28 de novembro de 2006. 